Article

\title{
Factors in a Sustainable Labor Market: Evidence from New College Graduates' Initial Job Placement in Korea
}

\author{
Daeheon Choi ${ }^{1}$, Chune Young Chung ${ }^{2, *}$, Mira Yoon ${ }^{2}$ and Jason Young ${ }^{3}$ \\ 1 College of Business Administration, Kookmin University, 77 Jeongneung-ro, Seongbuk-gu, \\ Seoul 02707, Korea; dhchoi@kookmin.ac.kr \\ 2 School of Business Administration, College of Business and Economics, Chung-Ang University, \\ Seoul 06974, Korea; meiluoyin@naver.com \\ 3 College of Business, Washington State University, Pullman, WA 99164, USA; bizfinace@naver.com \\ * Correspondence: bizfinance@cau.ac.kr; Tel.: +82-2-820-5544
}

Received: 3 February 2020; Accepted: 17 March 2020; Published: 19 March 2020

\begin{abstract}
Young Koreans have been experiencing stress and employment barriers due to progressively worsening employment issues since the late 1990s. College graduates spend excessive amounts of time job hunting, necessitating institutional and policy measures to improve their initial labor-market performance. We, therefore, attempt to empirically analyze the relevant factors. Focusing on sustainable job quality, company size, wages, and satisfaction levels for students' first jobs after graduation, and we specifically use college education quality and graduates' employment-preparation activities as independent variables and initial labor-market performance as a dependent variable. First, we measure education quality using vocational education and training, satisfaction with college education, and studying a language abroad. We find that they are positively associated with new graduates' initial labor-market performance. Second, we measure employment preparation activities using internship experience, certificates obtained, and scores on standardized English exams. Internship experiences are positively associated with new graduates' initial labor-market performance. These findings suggest that the Korean government should focus on establishing a sustainable labor market for new graduates and offer specific, diverse support programs to improve employment among young Koreans.
\end{abstract}

Keywords: sustainable labor market; college education quality; employment-preparation activities; initial labor-market performance

\section{Introduction}

In a 2014 Job Korea survey of 587 job seekers, $44.8 \%$ of respondents said that "building job competencies" is a priority in preparing for employment. "Accumulating experience to improve the resume" comes in second, with $32.9 \%$ considering it a priority, and "writing cover letters" is third, with $16 \%$. In addition, $50.4 \%$ agreed that the most important factor for achieving employment is building the capacity for a potential role at a company [1]. Therefore, it can be inferred that young Koreans invest a significant amount of time and effort into job-preparation activities. Hoping to enter and settle into the labor market successfully, they competitively build their job competencies and accumulate work-related experience to improve their resumes.

The gradual resolution of college graduates' employment problems and improvement of the overall utilization of high-quality manpower resources necessitates actively seeking institutional and policy measures that reduce the time college graduates take to obtain their first job and that improve their initial labor-market performance. By reducing the time, financial burden, opportunity costs, 
and stress associated with preparing for employment, such measures might be a fundamental solution for improving the quality of life, job satisfaction, and psychological stability of young people.

The specific conditions of their labor-market entry and movements (e.g., retirements, job changes, time off between jobs, reemployment, etc.) must be accurately surveyed and measured to find ways to improve the initial labor-market performance of young college graduates, who are the future of Korean society and a key manpower resource. College graduates' initial performance on labor-market entry and their success in mid- to long-term careers will differ significantly depending on their personal, social, and economic circumstances at graduation. Thus, it is necessary to more accurately understand their job-preparation activities and the details of their initial labor-market entry to identify appropriate and reasonable measures that conform to reality.

Since 2006, the Korea Employment Information Service has conducted an annual Graduates' Occupational Mobility Survey (GOMS) under joint supervision with researchers to provide mid- to long-term data to guide policy that can have a long-term positive impact on young graduates. Each year, the GOMS collects data from 18,000 two- to three-year and four-year college graduates (i.e., $5 \%$ of Korea's college graduates) from the previous year. Extensive cross-sectional surveys are conducted, collecting answers to over 1200 detailed and diverse survey items. Over a decade after its launch, the GOMS is now recognized as the most accurate and reliable study of its kind and contributes greatly to policy development and academic research that addresses young graduates' employment barriers.

Using the 2016 GOMS database, this study attempts to empirically analyze factors that affect Korean college graduates' performance on labor-market entry. It focuses on their initial performance- - that is, the quality, wages, and satisfaction levels of their first jobs after graduation. This study specifically focused on initial performance because initial labor-market performance can significantly affect midand long-term performance and entire careers.

Additionally, previous studies focus largely on return to schooling across various geographic locations and periods, finding a positive correlation between individuals' education and labor-market success. That is, better-educated people are more likely to find better jobs and earn higher wages and less likely to experience unemployment [2]. Studies such as those of Psacharopoulos [3,4] and Psacharopoulos and Patrinos [5] identified a relatively consistent global pattern over time. More recently, an ambitious study aggregated empirical findings from 139 countries and 819 household surveys, all of which have comparable estimates, database specifications, and sampling procedures [6]. The results reinforce previous studies' findings. Private returns to schooling are generally positive but decline as investment in education increases. In addition, women benefit more from higher education than men, and the estimated return on investment in education seems to be higher in low- and middle-income countries. However, the related study targeting developing countries [7] found no evidence that these countries have systematically higher returns to schooling than developed economies. In contrast to earlier studies, recent studies find that, globally, private returns to tertiary education are at an all-time high, followed by returns to primary and secondary schooling [8]. This is mostly because primary school attendance has become compulsory in many countries. Overall, these studies show that returns to schooling cannot be measured by a single parameter because they are influenced by individuals' characteristics and backgrounds [2].

This study aimed to demonstrate the relationships between education quality and job preparation and their respective sub-factors (i.e., the independent variables) and initial labor-market performance and its sub-factors (i.e., the dependent variable) and to identify positive factors. We used data from the 2016 GOMS to perform logistic and multiple regression, as well as frequency analyses for each of the variables. We also quantitatively and empirically verified the effects of education quality and degree of job preparation on initial labor-market performance (defined as employment quality and stability), size and type of organization, wage level, and job satisfaction. Through these results, this study aims to assist in alleviating the urgent social issue of employment barriers faced by young Korean graduates. It seeks feasible measures to improve initial labor-market entry, suggests effective institutional and policy implications, and proposes reasonable solutions to help increase graduates' quality of life and 
enhance Korean society's long-term stability. Moreover, successful higher education can only be understood in light of job placement for graduates and the creation of community partnerships that are socially vibrant, economically secure, and environmentally sustainable. Colleges and universities have an obligation to support local and regional communities.

\section{Institutional Background}

\subsection{College Education Quality}

South Korea's employment problems have gradually worsened since the International Monetary Fund (IMF) bailout in late 1997 [9] resulted in rapid social and economic changes. Government measures have been ineffectual, and the employment cliff and worsening unemployment-especially among young, highly skilled workers-have emerged as serious social problems since the mid-2000s. Young college graduates' failure to enter the labor market immediately after graduation creates hardships for them and their entire families, causing economic damage and lost opportunity costs. This delay also leads to national social problems, such as wasted human resources, weakened competitiveness, and increased public costs. Young unemployed Koreans suffer from major stress and employment barriers because of the persistence of these problems [10].

According to the Korea National Statistical Office, the unemployment rate among Koreans aged 15 to 29 was $9.9 \%$ in 2017, a 0.1 percentage point increase from 2016. One in 10 young people fail to get a job. Some structural reasons for persistent unemployment and the employment cliff include the rapid fall in Korea's economic growth rate since the mid-2000s, a decrease in private companies' growth, and the consequent decrease in high-skill jobs. Moreover, despite the slowing economic growth, over-education among young people continues, owing to Korea's unique emphasis on education. The widening gap between the growing number of highly educated graduates and the decreasing number of quality jobs results in a labor supply and demand mismatch. Accordingly, young graduates spend more time preparing for and waiting to enter the labor market and experience unprecedented chronic unemployment and stress.

Because these problems are worsening, Korean students competitively complete various job-related education and training programs conducted by businesses and public organizations. Students closely manage their grade point averages (GPAs) to obtain high quality and stable jobs as quickly as possible. Moreover, they actively apply for internships and concentrate on various job-preparation activities, such as obtaining certificates, taking standardized language exams, completing interviews, writing cover letters, taking resume writing training, and performing social service activities (to enhance their cover letters and resumes). Progressively, more students with wealthy parents also receive language training overseas [11].

\subsubsection{Vocational Education and Training}

The first sub-factor of college education quality is vocational education and training, which has been analyzed by several prior studies [12-15]. Vocational education and training refers to various programs that are implemented to cultivate and improve job-market performance. Vocational education and training encompasses all activities that train individuals to develop the necessary skills, knowledge, and attitudes for employment or founding start-ups. Although these programs have mainly been run by government agencies and businesses, more universities are now operating their own programs to improve their students' employment capacities. In fact, many universities currently receive financial support from the government to administer employment-related courses, technical training programs, job fairs, employment camps, employment clubs, job preparation and experience programs, employment aptitude tests, and career counseling programs. They also provide youth employment center and employment support expansion projects [12].

Considering these recent trends, we included career courses and employment programs established and operated by universities in the vocational education and training category. 
Workers whose skills have been cultivated and accumulated through vocational training may not only obtain quality jobs more easily as a result of their increased productivity, but also maximize their lifetime careers and total profits [13]. In this regard, Heslin [16] reported that vocational training increases individuals' employment probability, vocational skills, and income and improves job retention. Anderson [15] also reported that vocational training has a positive effect on the probability of job-market reentry after quitting a job. Park and Ban [17] demonstrated that vocational training positively affects employment probability and Joo [18] showed that participation in vocational education and training increases wages significantly. Jang [19] reported that graduates who have received vocational training are more likely to be employed by major companies.

\subsubsection{Satisfaction with College Education}

The second sub-factor in graduates' college education quality is satisfaction with college education. This refers to students' satisfaction with all education and training programs offered by their universities (i.e., courses in major and liberal arts studies, information technology (IT), other technical and practical training programs, and hobbies and extracurricular activities), educational environments and facilities, student support services, and their relationships with faculty and staff. Astin [20] first systematically presented this concept as the degree to which students positively perceive and are satisfied with their academic relationships. Overall satisfaction with one's college education is reported to increase its efficiency and affect the academic abilities and efficacies of individual students directly and indirectly by energizing college life [21]. Satisfaction with university career support has become increasingly important as the employment problem among graduates has worsened and Korean labor-market competition has intensified.

The studies above showed that satisfaction with university education positively affects job performance by adopting it as a new independent variable in analyzing young graduates' labor-market performance. However, a limitation arises if the dependent variable-employment performance-is quantitative (job-market success, employment duration, or the employment maintenance ratio). Thus, this study examined the influence of satisfaction with education using job quality, job type, wage level, and job satisfaction as sub-factors of achievement in the labor market, which is the dependent variable.

\subsubsection{Studying Language Abroad}

The third education quality sub-factor is studying a language abroad, which has recently attracted substantial interest and enthusiasm in Korea. It is an important factor in Korea's labor-market performance, and its importance is directly related to the recent intensification of job-market competition and rapid globalization since the end of the 20th century.

The resulting excellent language skills are an attractive selection criterion for employers. Such experience is a powerful "plus factor" that gives labor-market entrants a substantial advantage in light of the long-term unemployment rate and fierce job-market competition. Selecting studying language abroad as an education quality sub-factor allowed us to verify its effect on labor-market performance and its sub-factors.

\subsection{Employment-Preparation Activities}

This refers to all practical and concrete activities that students can engage in to achieve the ultimate goal of obtaining employment and improving employment quality (among other outcomes) [22]. It covers a wide variety of activities, including GPA management, studying for official language tests, acquiring certifications, attaining internship experience, searching for job information, participating in employment support programs, taking courses on careers and employment, submitting job applications, receiving job interviews, and so on.

Employment-preparation activities can be divided into individual activities and those that must be supported at university level. Personal activities include GPA management, language exam preparation, 
certifications, and job experience. The school support-activity scope includes establishing courses related to workplace readiness courses, operating career and employment programs, and offering counseling programs to relieve job stress.

Systematic and organized job preparation activities can positively affect college graduates' initial labor-market performance and subsequent turnover, thereby properly compensating students for their efforts. In this sense, by choosing employment-preparation activities as an independent variable, this study demonstrates its effect on graduates' labor-market performance and its sub-factors.

\subsubsection{Internship Experience}

The first sub-factor of employment-preparation activities is internship experience. Internships have also been analyzed by several prior studies and have generally been found to have a positive effect on students' labor-market performance after graduation. [23,24]. According to Jung and Cho [25], college internship experience increases students' proficiency and professionalism in their majors, increasing their competitiveness in the labor market, and in turn, resulting in better labor-market entry. Referring to this analysis, we observe that college internships and the job experiences of young graduates must be approached carefully. Because useful internship experiences that harmoniously combine a student's major with a job significantly affect the probability of securing regular, permanent employment, government agencies and businesses must supplement the related systems and policies so that desirable and efficient internship experiences are available during college.

In this regard, Roh and Hur [26] analyzed college graduates' experience with vocational training and internships on the basis of internships' psychological and economic effects, as well as job satisfaction experienced by the graduate. According to this study, vocational training and internships that are closely linked to graduates' aptitudes and specialties enhance job satisfaction and efficacy.

Prior studies [21-23] have demonstrated the net benefits of well-organized training or internship programs in the case of distinct medium- and long-term goals and plans. In addition, after considering various related factors, such as the type of internship, the host organization, and the connection with the student's major, analyses have found that the internship system experienced during university years significantly influences initial labor-market performance. Thus, this study investigated the relationship between internship experience and job quality, job type, wage level, and job satisfaction upon labor-market entry.

\subsubsection{Obtaining Certificates}

Certification acquisition, the second sub-factor of employment-preparation activities, has also been analyzed in various ways by prior studies. Certifications serve as a representative indicator of the degree and results of college graduates' preparatory activities. They can also refer to job competency certificates, which formally provide an objective assessment of an individual job-related skill [27]. However, different studies find differing effects on employment performance. Ihm and Yoo [28] and Lee [29] reported that the acquisition of certifications affects employment performance positively. Conversely, according to Park and Ban [17] and Jang [19], certifications have no positive effects. Lee et al. [30] reported that the effects differ depending on the type and nature of the certification.

By contrast, certifications have been reported to affect employment status and quality negatively [19] or to have no significant effect on obtaining high-quality jobs [17]. Thus, the evaluation contents and processes of certifications may be inappropriate, insufficient, or unreliable, making certifications ineffective in improving labor-market performance [19]. We must, therefore, carefully select the certification type and consider its authenticity, difficulty, and specialty.

According to the 2014 GOMS, $63.8 \%$ of Korean college graduates, $68.6 \%$ of vocational college graduates, and $60.5 \%$ of four-year college graduates hold certifications [22]. They hold 1.89, 1.92, and 1.87 certifications on average, respectively. Similarly, this study examined the certificate acquisition effect on college graduates' initial labor-market performance by selecting it as a preparatory activity sub-factor. 


\subsubsection{Standardized English Exams}

The third preparatory activity sub-factor is taking standardized English exams. For job seekers, taking an officially recognized English examination, such as the TOEIC or TEPS, implies a particular score, which serves as an official competency certificate that simultaneously proves the effort, time, and result of this process.

This is increasingly more important because an official English score, a clear testament to excellent English language skills in the unstable Korean labor market, is a priority among the several prerequisites for employment. Studies report that it has a greater effect on four-year college graduates' employment performance than it does on vocational college graduates' [31,32]. Referring to previous studies' results, this study evaluated this variable's effect on college graduates' initial labor-market performance by including it as a preparatory activity sub-factor.

\subsection{Initial Labor-Market Performance}

This study's dependent variable is college graduates' labor-market performance, with a specific focus on their initial performance. We focused on initial labor-market performance because, if the condition and quality of the first job on labor-market entry are high, then the trial and error associated with early retirement, turnover, and re-employment can be substantially reduced; mid- and long-term careers and lifelong work experience are greatly improved. To describe college graduates' labor-market entry performance, researchers previously relied on quantitative variables, such as employment status, probability of employment success, etc. However, since 2010, studies have used more qualitative and in-depth variables. Specific example variables include employment quality and stability [33], type of workplace [34], wage level [31,35,36], wage satisfaction [37], job satisfaction [31], and occupational aspirations [38]. Consequently, we selected job quality, job type, wage level, and job satisfaction as initial labor-market performance sub-factors.

\subsubsection{Permanent Contract}

The first sub-factor of initial labor-market performance, employment type (regular or non-regular position), refers to the quality, level, and stability of college graduates' first jobs upon labor-market entry. As we focused on the initial labor-market performance of college-educated youth, this study analyzed the quality of employment at workplaces associated with these jobs. As seen in Figure 1, the recent gradual increase in the employment rate of non-regular workers owing to greater labor-market flexibility and short-term revenue reductions has resulted in structural discrimination in wages, working conditions, and treatment across regular and non-regular workers, and has become a major social issue [39]. The gaps in wages, working conditions, and treatment lower the level of job, job-duty, and wage satisfaction, as well as productivity, psychological stability, and quality of life. These gaps cause constant hierarchical conflicts between regular and non-regular workers [40].

The Moon Jae-in administration, which took office in 2017, is therefore making various efforts to create quality jobs and cultivate high-quality human resources by actively implementing relevant policies, such as designating job creation as a core national task and establishing a presidential direct job committee. As part of these efforts, the government is urging the public sector to take the lead in solving unemployment and structural discrimination against non-regular workers by calling for the conversion of non-regular workers to regular workers.

Thus, rather than applying the conservative principle of emphasizing regular workers in job policies, it is necessary to actively understand emerging trends and to identify and utilize key trends quickly and accurately. Policy and institutional flexibility and resilience must be developed to adapt easily to the current environment.

This study sought, therefore, to empirically analyze the factors affecting the employment quality of college graduates, that is, regular or non-regular positions. 


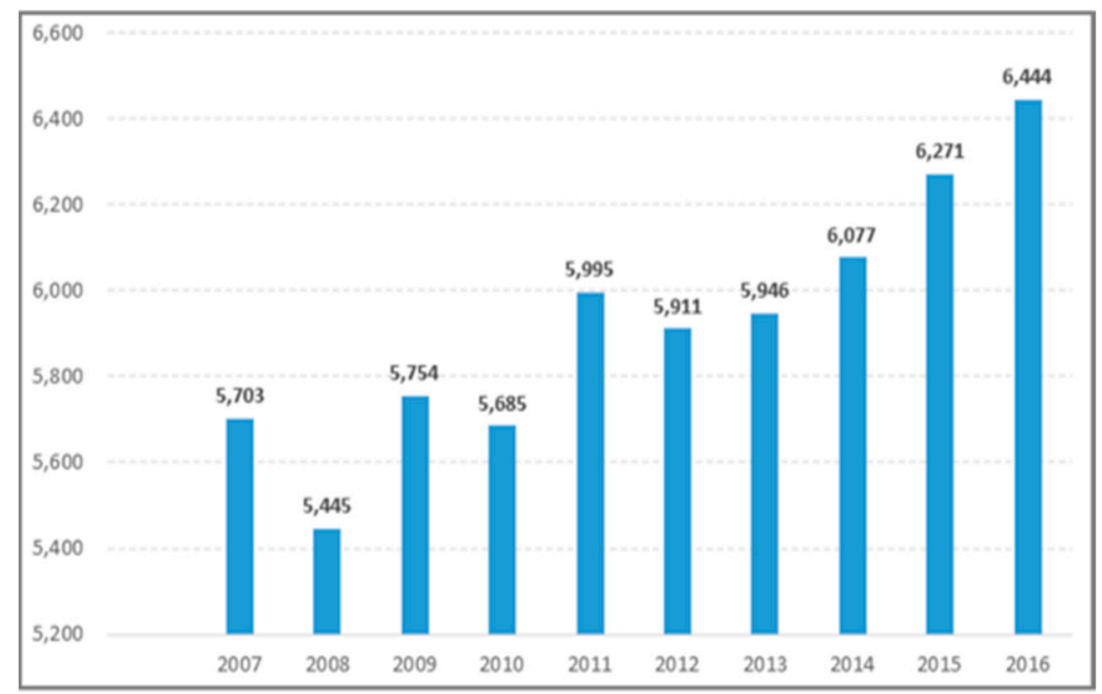

Figure 1. The number of non-regular workers. Source: a survey of the economically active population by job type [41].

\subsubsection{Company Size (Major Companies or Small and Medium Enterprises (SMEs))}

The second sub-factor that constitutes college graduates' initial labor-market performance is company size, which indicates the type of workplace that offers college graduates' their first job after labor-market entry. This study divided companies into major companies and small and medium enterprises (SMEs) based on the size of the workplace (i.e., the number of employees) and uses this definition to analyze the initial labor-market performance and factors that affect it.

The rapid changes in Korea's labor market have raised college graduates' expectations of high-quality employment. Although a stable job provides a means of living, graduates tend to hold out for better jobs that confer higher social status, reputation, and honor [42]. In addition, the wage level, promotion period, working environment, and welfare system differ depending on the size and type of workplace. Thus, despite employment difficulties, young graduates are more reluctant to work for SMEs, in comparison to large companies. However, despite their aspirations, their actual first jobs are most commonly regular jobs in SMEs, followed by non-regular jobs in SMEs. To a lesser degree, they secure regular jobs in major companies and non-regular jobs in major companies, as shown in Table 1.

Table 1. The forms of employment at college graduates' first job placement (\%).

\begin{tabular}{cccccc}
\hline & $\mathbf{2 0 1 0}$ & $\mathbf{2 0 1 1}$ & $\mathbf{2 0 1 2}$ & $\mathbf{2 0 1 3}$ & $\mathbf{2 0 1 4}$ \\
\hline SME/Regular Job & 41.3 & 41.1 & 40.2 & 36.9 & 34.3 \\
SME/Non-Regular Job & 18.2 & 21.3 & 19.7 & 19.4 & 21.2 \\
Major Company/Regular Job & 10 & 11.2 & 13.2 & 11.8 & 10.4 \\
Major Company/Non-Regular Job & 4.9 & 6.5 & 7.1 & 5.9 & 6.1 \\
Total & 74.4 & 80.1 & 80.2 & 73.9 & 72.1 \\
\hline Unemployed & 25.6 & 19.9 & 19.8 & 26.1 & 27.9 \\
\hline
\end{tabular}

Some prior studies analyze employment status with major companies and small businesses and factors related to the labor-market entry performance of graduates. According to Kang [33], younger workers in Seoul have a higher proportion of jobs at large companies. Park [43] showed that men were more likely than women to work at large companies. Referring to these previous studies, this study selected the type of workplace (i.e., major companies versus SMEs) as a sub-factor of initial labor-market performance. This study empirically analyzes the independent variables and sub-factors that affect initial labor-market performance. 


\subsubsection{Wage Level}

The third sub-factor constituting initial labor-market performance is wage level, including monthly salaries, weekly pay, hourly rates, or other types of monetary compensation to employees for their work [18]. The 2014 average monthly wage for college graduates' first jobs was 1,729,000 Korean won, with averages of 191,500 and 1,560,000 won for men and women, respectively; the average compensation package for men exceeded that for women by 355,000 won [44]. By school type, the average salary was $1,563,000$ and $1,822,700$ won for vocational and four-year college graduates, respectively, a difference of 264,000 [44].

The wage gap between regular and non-regular workers is far more serious than the genderand school-based gaps. In June 2016, the average monthly wage of all workers was 2,833,000 won, but it was 32,830,000 for regular workers and 1,445,000 for non-regular workers [45]. Thus, this study adopted wage level as a sub-factor of initial labor-market performance and empirically analyzed the independent variables and sub-factors affecting it.

\subsubsection{Job Satisfaction}

The fourth sub-factor of initial labor-market performance is job satisfaction, which is an important concept in understanding the personal psychology of workers. Job satisfaction is defined as psychological and emotional satisfaction that workers subjectively feel regarding the workplace [46]. Job and job-duty satisfaction are conceptually similar and closely related. Job satisfaction refers to a positive psychological state, the satisfaction of individual needs, and the subjective state of emotional satisfaction $[47,48]$. Job-duty satisfaction, however, is a more comprehensive and complex consideration of various factors related to workplace and environmental conditions, including job responsibilities. Thus, it is more appropriate for this study to utilize job satisfaction than job-duty satisfaction as a component of the dependent variables because this study aims to qualitatively analyze the initial job-market performance of college graduates.

\subsection{Designing the Research Model}

Research models are used to understand and analyze scientific phenomena objectively and rationally and as useful standards for effectively interpreting and explaining those phenomena [49]. Thus, designing a research model is a prerequisite for a scientific study and is a fundamental, essential step for implementing research in various social sciences topics [50].

\section{Formulating the Research Questions}

We first investigate whether college education quality affects graduates' initial labor-market performance, and, second, whether their employment-preparation activities affect their initial labor-market performance. Thus, this study establishes two specific research questions and eight sub-questions, as follows.

(1) Research question 1: Does college education quality affect graduates' initial labor-market performance?

- 1-1: College education quality has a statistically significant effect on the quality of college graduates' first job (regular/non-regular).

- 1-2: College education quality has a statistically significant effect on the size of college graduates' companies (major company/SME).

- 1-3: College education quality has a statistically significant effect on college graduates' wage levels.

- 1-4: College education quality has a statistically significant effect on college graduates' job satisfaction. 
(2) Research question 2: Do college graduates' employment-preparation activities affect their initial labor-market performance?

- 2-1: College graduates' employment-preparation activities have a statistically significant effect on the quality of their first job (regular/non-regular).

- 2-2: College graduates' employment-preparation activities have a statistically significant effect on their company size (major company/SME).

- 2-3: College graduates' employment-preparation activities have a statistically significant effect on their wage levels.

- 2-4: College graduates' employment-preparation activities have a statistically significant effect on their job satisfaction.

\section{Research Methodology}

\subsection{Data Collection and Selection of Measurement Tools}

\subsubsection{Data Collection and Introduction}

This analysis' basic data source is a large-scale social investigation dataset from 2016 that tracks college graduates' career paths in the labor market (GOMS). It has been jointly collected annually by the Korea Employment Information Service and Hankook Research. We searched for appropriate data from social investigation analyses or relevant institutes that could verify and analyze the factors that affect Korean college graduates' initial performance after labor-market entry. When investigating prior studies and news articles, we came across the GOMS. Investigation led to the conclusion that the data is sufficiently trustworthy to use as this study's core data. We then downloaded the raw data from the Korea Employment Information Service's official website (https://survey.keis.or.kr/goms/goms01.jsp).

The 2016 GOMS dataset was collected from September 1, 2016 to November 30, 2016; 18,199 college graduates were surveyed among students who graduated from two-, three-, and four-year colleges between August 2014 and February 2015 in Korea. Within two years of graduation, the sampled graduates had entered the labor market and acquired their first jobs. At the time of data collection, they were employed at the same workplace, had transferred to another job (or were attempting to do so) after quitting their first job, were preparing to open their own businesses, or had obtained (or were attempting to obtain) another form of employment. One month prior to data collection (August 2016), we conducted a preliminary investigation to determine whether this demographic suited our research purpose. Afterward, we asked the 18,199 final survey candidates 1297 questions and collected their answers. The questions covered a variety of items, including personal information, family background, college education, job hunting experience, certificates, internship experiences, past work experiences (including both part- and full-time experiences), level of satisfaction with past and present jobs (specific and general criteria), initial job-market performance, and other related items. This preliminary investigation of the broad dataset, as well as prior studies, led to the following selection of measurement tools.

\subsubsection{Selection of Measurement Tools and Data Coding}

\section{(1) Number of Observations for Analysis}

In 2016, at the time of data collection, 12,799 of the 18,119 survey sample graduates in the dataset had succeeded in acquiring their first job within two years of graduation. This included those who were still in their first job at the time of data collection, had quit their first job prematurely, had transferred to a different job, had exited and re-entered the labor market, had quit their first job but failed to re-enter the labor market, and those who were attempting to open their own businesses. In other words, we define our sample as college graduates who have acquired their first job, and our sample selection 
process reveals that 12,799 subjects meet the conditions specified in Table 2. These are used in our empirical analysis.

Table 2. Independent variables, dependent variables and criteria for measurement in GOMS 2016.

\begin{tabular}{cccc}
\hline Variable & Variable Name & Subfactors & Number \\
\hline & Quality of college & Vocational education and training experience & 12,799 \\
Independent variable & Seducation & Satisfaction of college education & 12,799 \\
& & Language study abroad experience & 12,799 \\
& Preparatory activities for & Internship experience & 12,799 \\
& employment & Obtaining certificates & 12,799 \\
Dependent variable & & Taking standardized English exams & 12,799 \\
& Initial performance in & Job quality & 12,799 \\
& the labor market & Size of the company & 12,799 \\
& & Wage level & 12,799 \\
& & Job satisfaction & 12,799 \\
\hline
\end{tabular}

(2) Independent Variables and Sub-factors

After reviewing relevant prior studies, we selected independent variables and their sub-factors that may influence the quality of the 12,799 college graduates' first jobs. Vocational education and training, satisfaction with college education, and studying languages abroad are closely related to graduates' satisfaction with their college education. These same factors make college education an essential resource or tool for employment. Thus, we select college education quality as a top-level factor that encompasses these three sub-factors; college education quality is the first independent variable.

Additionally, internship experience during or after college, certifications, and official English tests are valid indicators of career-preparation activities and the effort, time, and opportunity costs that go into them; thus, they are important factors that constitute career preparation activities as a tool and strategy. We therefore define employment-preparation activities as a top-level factor that encompasses these three sub-factors, and we use it as the second independent variable.

(3) Dependent Variable and Sub-factors

This study's ultimate goals are to identify factors that positively affect college graduates' initial job-market performance and to suggest ways to improve their overall performance. Thus, we use college graduates' initial job-market performance as the dependent variable and select sub-factors that can measure this variable.

Relevant prior studies measure job-market performance by focusing on whether a job is regular and permanent and whether it is at a large corporation. In this regard, Kang [33] reported that younger job candidates living in Seoul have a greater chance than older candidates of getting a job with a large corporation or some other regular, permanent job. Park [43] reported that male candidates have a greater chance than female candidates of obtaining work at large corporation or permanent jobs. Lee [29] and Park [43] reported that four-year college graduates have a better chance of getting jobs with large corporations than vocational college graduates have. Chae and Kim [10] and Park [43] concluded that math, science, and engineering majors have a greater chance of getting jobs with large corporations than other majors. Furthermore, Kim [51] and Park and Cheon [52] demonstrated that language training experience overseas has a positive effect on obtaining large corporation or permanent jobs.

Whether a job is regular or permanent as opposed to contract-based or temporary, and whether it is with a large company or an SME, are the biggest concerns of all Korean college graduates. These factors must be included when discussing any country's job market. Prior studies, therefore, also focus on these factors. In this context, we select whether the job is permanent and with a large corporation or SME as sub-factors of our dependent variable, initial labor-market performance. 
Additionally, we select the wage level as another sub-factor of the dependent variable. This selection is based on multiple studies. The studies of Kim [36] concluded that men's wages are higher than women's wages. Choi and Kim [41] reported that graduates of colleges in metropolitan areas earn higher wages than those of graduates of colleges in non-metropolitan areas, and Choi [32] found that official English test scores significantly affect wage levels.

Finally, we select job satisfaction as another sub-factor of the dependent variable based on the studies of Gilson and Durick [53], who found that personal characteristics affect job satisfaction. Cha and Chu [42] also reported that individuals whose jobs match their majors are generally more satisfied with their jobs than those whose do not.

As outlined so far in this study, the dependent variable is college graduates' initial labor-market performance; its four sub-factors are whether the job is permanent, whether it is with a large corporation, wage, and job satisfaction. Among these, whether the job is permanent is renamed "employment type," and whether the job is at a large corporation is renamed "company size." Wage reflects the average monthly wage at the first job, and job satisfaction refers to subjective overall satisfaction with the first job.

As discussed previously, prior studies have focused on subjects' personal characteristics (e.g., gender, age, major, college, family background, area of residence, etc.) as independent variables and attempted to analyze their effects on the dependent variable. Only a few recent studies have attempted to perform multi-lateral analyses by utilizing more qualitative and sophisticated independent variables, such as vocational training, experience studying abroad, internship experience, certification acquisition, and standardized English tests. However, even many of these that have used such profound independent variables have chosen quantitative dependent variables, such as the success rate of employment, the possibility of employment, the time it takes to acquire a first job, the duration of employment, and so on. We suggest that dependent variables that reflect employment performance should be more qualitative in future studies, so that they can indicate employment quality in more detail than the more common quantitative dependent variables.

With this need and rationale in mind, we focused on college graduates' qualitative achievements in terms of employment or job quality and analyzed how these achievements are affected by qualitative, content-based dependent variables, particularly education quality and employment-preparation activities. We believe that this analysis will help identify ways to utilize Korea's workforce of highly intelligent college graduates more actively and efficiently.

(4). Data Analysis

We used the SPSS Statistics 21.0 statistics program to analyze the final extracted/selected data and to test the research questions. The primary data analysis methods are as follows.

First, we perform a frequency analysis of the personal characteristics (gender, age, major field of study, type of college, region of university, etc.) of the 12,799 subjects surveyed. Frequency analysis is a basic statistical survey method used to identify the survey respondents' overall characteristics, distributions, and percentages, as well as the survey sample's overall characteristics and orientation [54].

Second, we perform a logistic regression analysis to test Hypotheses 1-1, 1-2, 2-1, and 2-2 by demonstrating the relationships of the independent variables with job quality (regular or non-regular) and company size (major company/SME). It is typical to use logistic regression when the independent variables are quantifiable or graded quantitatively (including equivalent scales) and the dependent variables are binary, taking values such as "yes/no," "have/don't have," and "whether or not" [55].

In summary, the binary logistic regression model [12] is given by

$$
\operatorname{Ln}\left(\frac{\mathrm{p}}{1-\mathrm{p}}\right)=\beta_{0}+\beta_{1} X_{1}+\beta_{2} X_{2}+\cdots+\beta_{n} X_{n}
$$

To perform a logistic regression, the dependent variables must be binary variables that are coded as zero and one in the statistical analysis process. For example, for a dependent variable consisting 
of "yes" and "no" answers, the analysis is performed after coding "yes" as one and "no" as zero. The independent variables consist of equidistant scales of one to three points, one to five points, or one to seven points, or, if they are quantitative variables, such as age, height, or weight, the pertinent number can be entered accordingly. If the independent variables are not quantitative but rather nominal measures, such as gender or smoking status, they should be converted to dummy variables [56]. For example, gender can be coded as one for men and zero for women.

Third, we perform multiple regression analyses to test Hypotheses 1-3, 1-4, 2-3, and 2-4 by demonstrating the relationships of the independent variables with wage level, which is a quantitative dependent variable (converted to logarithms) and job satisfaction, which is on the same scale. Multiple regression is a common analytical method used in analyzing causality across multiple independent variables and a single dependent variable [57].

The multiple regression analysis model is summarized as follows.

$$
Y_{i}=\beta_{0}+\beta_{1} X_{1}+\beta_{2} X_{2}+\cdots+\beta_{p} X_{p}+e_{0}
$$

(5) Extracting the Criteria for Measurement and Coding

Based on our review of prior studies, we selected independent and dependent variables (and their sub-factors) to suit our study's purpose and direction. Through an extensive overall examination of the 2016 GOMS data, we extracted appropriate measurement tools. These results are described in Table 2.

Six of the variables and factors chosen based on our review of the literature and data analysis-vocational education and training experience, studying language abroad, internship experience, certificates obtained, taking standardized English exams, and job quality-take the form of "Yes/I have", “No/I haven't," or "I don't know." We assume that "I don't know" implies having no experience with vocational training, study abroad, certification acquisition, or official English exams and, thus, process that answer as "No/I haven't." Thus, in these cases, we code both "No/I haven't" and "I don't know" as zero and "Yes/I have" as one. Additionally, if subjects were employed in a regular position at the time of quitting their first job or they were still at their first job at the time of data collection, we code it as one. If they were employed in a non-regular position, we code it as zero.

As for the type of company, it is possible to apply many different criteria, such as the industry (e.g., upper category, medium-level category, specific category, etc.), the company size, the type of work (e.g., presence required at the workplace every day or every other day or working from home, etc.). Nevertheless, depending on the number of employees, we categorize the subjects' initial jobs as with either an SME or a major company. The data classify enterprises as having 1-4, 5-9, 10-29, 30-49, 50-99, 100-299, 300-499, 500-999, or 1000 or more employees. If there are less than 300 employees, we call the enterprise an SME; otherwise, we call it a major company. We code SMEs as zero and major companies as one.

Next, satisfaction with college education and job satisfaction are measured using a five-point Likert scale (1: strongly disagree; 2: disagree; 3: neutral; 4: agree; 5: strongly agree), which we leave intact for our analysis. Finally, wage levels are recorded in the form of the subjects' first monthly wage in 10,000 Korean won, which we convert to natural logarithms (Log). The conversion was performed using Microsoft Excel.

\section{Empirical Analysis}

\subsection{Testing and Interpreting the Research Questions}

We analyze research questions 1 and 2 and their sub-research questions to examine the effects of the quality of education received by Korean college graduates and their employment-preparation activities on their initial labor-market performance. We perform logistic regression and multiple regression analyses to test the related hypotheses. The results of this analysis are summarized as follows: 
The findings showed that among the sub-factors of preparatory activities standardized English examinations have the greatest influence on job quality and company size, whereas certification has the second-greatest influence. Internship experience was shown to have the second-largest influence on company size. Thus, we verify that professionally acknowledged certificates are valued more highly than unacknowledged certificates or internships that are not clearly linked to majors or promised benefits.

Thus, based on these results, to help college graduates enter the labor market more effectively, various appropriate measures should be considered and implemented. For example, students should have meaningful internship opportunities closely connected to their majors, information about certificates that have public confidence, professionally and officially recognized English examinations, and effective educational opportunities offered at low prices. Although we demonstrated that internships, certifications, officially recognized English examinations, and so on are clearly proven to significantly influence employment outcomes and quality, only 13.27\% (1696 subjects), 32.94\% (4210 subjects), and 31.29\% (3998 subjects) of all survey subjects had engaged in them, respectively. Thus, more educational opportunities should be provided regarding employment-preparation activities, but policymakers should strive to solve problems stemming from inequalities among various opportunities.

\subsubsection{Testing and Interpreting Research Question 1}

To test research question 1, we conduct regression analyses for each of the four sub-questions and expect that more than half of them will be confirmed. We perform a logistic regression analysis because the dependent variables (job quality and the size of the company) for research questions 1-1 and 1-2 are binary variables (yes/no). We also perform multiple regression analyses because the dependent variables for research questions 1-3 and 1-4 are quantitative (wage level) and interval variables (job satisfaction).

First, to test Hypothesis 1-1, we perform a logistic regression of college graduates' job quality (regular/non-regular) on their college education quality and three sub-factors. The results of the analysis are summarized in Table 3.

Table 3. Results of regressing job quality on college education quality.

\begin{tabular}{cccc}
\hline & $\beta$ & S.E. & $\operatorname{Exp}(\boldsymbol{\beta})$ \\
\hline Vocational education and training experience & $0.160^{* *}$ & 0.039 & 1.174 \\
Satisfaction with college education & $0.094^{* *}$ & 0.018 & 1.099 \\
Studying language abroad & $0.138^{*}$ & 0.054 & 1.148 \\
Constant & 0.058 & 0.062 & 1.060 \\
\hline
\end{tabular}

Hosmer and Lemeshow test $=0.181$, Nagelkerke R-Squared $=0.006$

Dependent variable: job quality ${ }^{* * *}, * *$, and ${ }^{*}$ denote statistical significance at the $1 \%, 5 \%$, and $10 \%$ levels, respectively.

In the logistic regression, the Hosmer-Lemeshow test is performed to verify the validity of the model. According to Table 3 , the $p$-value of the Hosmer-Lemeshow test is 0.181 , which is higher than 0.05 , proving the validity of the regression model. The explanatory power of this model is $0.6 \%$.

Table 3 shows that the odds ratios of all items are greater than one, meaning that all three items have a positive effect on employment as a regular worker. Specifically, among the three sub-factors of college education quality, the odds ratio of vocational education and training experience is 1.174, meaning that having vocational training experience increases the odds of working as a regular worker by 1.174 times.

When comparing the degree of influence on job quality, vocational education and training experience have the greatest influence, followed by studying languages abroad and satisfaction with college education. 
Next, the logistic regression model is used to examine whether college education quality affects company size to test Hypothesis 1-2.

The results of the analysis are summarized in Table 4.

Table 4. Results of regressing company size on college education quality.

\begin{tabular}{cccc}
\hline & $\boldsymbol{\beta}$ & S.E. & $\operatorname{Exp}(\boldsymbol{\beta})$ \\
\hline Vocational education and training experience & $0.222^{* *}$ & 0.039 & 1.225 \\
Satisfaction with college education & -0.021 & 0.018 & 0.980 \\
Studying language abroad & $0.177^{* *}$ & 0.054 & 1.194 \\
Constant & -0.707 & 0.063 & 0.493 \\
\hline
\end{tabular}

Hosmer and Lemeshow test $=0.109$, Nagelkerke R-Squared $=0.014$

Dependent variable: size of the company. ${ }^{* * *},{ }^{* *}$, and ${ }^{*}$ denote statistical significance at the $1 \%, 5 \%$, and $10 \%$ levels, respectively.

According to Table 4 , the $p$-value of the Hosmer-Lemeshow test is 0.109 , proving the validity of the regression model, and the explanatory power of the dependent variable for the independent variables is $1.4 \%$.

As a result, among the three sub-factors of college education quality, the odds ratio of vocational education and training experience is 1.225 , meaning that having vocational education and training experience increases the odds of working for a large company by 1.225 times. However, the odds ratio of satisfaction with college education is less than one. Furthermore, the $p$-value is 0.264 , which is over 0.05 . Thus, satisfaction with college education does not affect company size.

When comparing the degree of influence on company size, vocational education and training experience has the greatest influence.

Next, multiple regression is conducted for college education quality and the three sub-factors and wage levels to test Hypothesis 1-3. The results of the analysis are summarized in Table 5.

Table 5. Results of regressing wage level on college education quality.

\begin{tabular}{cccc}
\hline & $\boldsymbol{\beta}$ & S.E. & $\mathbf{t}$ \\
\hline Vocational education and training experience & $0.137^{* *}$ & 0.009 & 4.236 \\
Satisfaction with college education & $0.091^{* *}$ & 0.004 & 22.068 \\
Studying language abroad & $0.047^{* *}$ & 0.013 & 5.393 \\
Constant & & 0.015 & 325.434 \\
\hline
\end{tabular}

R-Squared $=0.041$, Adjusted R-squared $=0.040, \mathrm{df1}=3, \mathrm{~F}=180.076, \mathrm{p}=0.000$,

Durbin-Watson $=1.942$

Dependent variable: wage level. ${ }^{* * *}, * *$, and ${ }^{*}$ denote statistical significance at the $1 \%, 5 \%$, and $10 \%$ levels, respectively.

First, the overall explanatory power of this model is $4.0 \%$. The F-statistic of the analysis of variance is 180.076 , the $p$-value is 0.000 , and the Durbin-Watson statistic is 1.942 .

The validity of the multiple regression model is confirmed, as it meets the various standard value requirements. The results show that all variables have statistically significant effects on wage level. In other words, the standardized coefficient $\beta$ is $0.137,0.091$, and 0.047 for vocational education and training experience, satisfaction with college education, and studying language abroad, respectively, meaning that all three factors have a statistically significant positive effect on wage level. Vocational training experience has the greatest influence, followed by satisfaction with college education and studying language abroad.

Next, we conduct a multiple regression analysis for college education quality and job satisfaction (sub-factors of initial labor-market performance) to test Hypothesis 1-4. The results of the analysis are summarized in Table 6. 
Table 6. Results of regressing job satisfaction on college education quality.

\begin{tabular}{cccc}
\hline & $\boldsymbol{\beta}$ & S.E. & $\mathbf{t}$ \\
\hline Vocational education and training experience & -0.009 & 0.017 & -1.114 \\
Satisfaction with college education & $0.120^{* *}$ & 0.008 & 52.355 \\
Studying language abroad & $0.050^{* *}$ & 0.023 & 6.274 \\
Constant & & 0.027 & 86.882 \\
\hline
\end{tabular}

R-Squared $=0.179$, Adjusted R-Squared $=0.178, \mathrm{df} 1=3, \mathrm{~F}=129.315, \mathrm{p}=0.000$, Durbin-Watson $=1.956$

Dependent variable: Job satisfaction. ***, **, and * denote statistical significance at the $1 \%$, $5 \%$, and $10 \%$ levels, respectively.

According to Table 6, the overall explanatory power of college education quality for job satisfaction is $17.8 \%$, with an F-statistic of 129.315 and a $p$-value of 0.000 . The Durbin-Watson statistic is 1.956, and the variance inflation factor (VIF) is 1.000 1.002 $(<10.0)$. Thus, this multiple regression equation is statistically significant, and the independence of the residuals is ensured without a multicollinearity problem. These results show that two of the three factors have statistically significant effects on job satisfaction. Vocational training experience, however, has no significant effect. More specifically, the standardized coefficient $\beta$ of satisfaction with college education is 0.120 , and that of studying language abroad is 0.050 , indicating that they have statistically significant positive effects on job satisfaction.

\subsubsection{Testing and Interpreting Research Question 2}

As in research question 1, we perform logistic regressions for sub-questions 2-1 and 2-2 and multiple regressions for sub-questions 2-3 and 2-4. Again, more than half of the four hypotheses should be confirmed. First, we conduct a logistic regression of job quality on employment-preparation activities to test Hypothesis 2-1. The results of the analysis are summarized in Table 7.

Table 7. Results of regressing job quality on employment-preparation activities.

\begin{tabular}{cccc}
\hline Model & $\boldsymbol{\beta}$ & S.E. & $\operatorname{Exp}(\beta)$ \\
\hline Internship experience & $0.143^{* *}$ & 0.054 & 1.154 \\
Obtaining certificates & $0.172^{* *}$ & 0.039 & 1.188 \\
Taking standardized English exams & $0.177^{* *}$ & 0.039 & 1.193 \\
Constant & 0.297 & 0.027 & 1.346 \\
\hline
\end{tabular}

Hosmer and Lemeshow test $=0.885$, Nagelkerke R-Squared $=0.005$

Dependent variable: Job quality. ${ }^{* * *}, * *$, and ${ }^{*}$ denote statistical significance at the $1 \%, 5 \%$, and $10 \%$ levels, respectively.

According to Table 7 , the $p$-value of the Hosmer-Lemeshow test is 0.885 , proving the validity of the regression model, and the explanatory power of the independent variables for the dependent variables is $0.5 \%$. The logistic regression model used to examine whether college graduates' employment-preparation activities affect job quality shows that because the odds ratio of every item is greater than one, all three positively affect employment as a regular worker. Among the three sub-factors of preparatory activities, the odds ratio of taking standardized English exams is 1.193, which means that it increases the odds of being employed as a regular worker 1.193 times. When comparing the degree of influence on job quality, taking English exams has the greatest influence, followed by obtaining certificates and internship experience. Because all three items have a positive effect on job quality, Hypothesis 2-1 is confirmed.

Next, we conduct a logistic regression of company size on employment-preparation activities to test Hypothesis 2-2. The results of the analysis are summarized in Table 8. 
Table 8. Results of regressing company size on preparatory activities.

\begin{tabular}{cccc}
\hline Type of Activity & $\boldsymbol{\beta}$ & S.E. & $\operatorname{Exp}(\beta)$ \\
\hline Internship experience & $0.146^{* *}$ & 0.057 & 1.157 \\
Obtaining certificates & $-0.137^{* *}$ & 0.052 & 0.959 \\
Taking standardized English exams & $0.314^{* *}$ & 0.041 & 1.369 \\
Constant & -0.263 & 0.027 & 0.769 \\
\hline
\end{tabular}

Hosmer and Lemeshow test $=0.764$, Nagelkerke R-Squared $=0.174$

Dependent variable: Company size. ***,**, and * denote statistical significance at the $1 \%, 5 \%$, and $10 \%$ levels, respectively.

According to Table 8 , the $p$-value of the Hosmer-Lemeshow test is 0.764 , proving the validity of the regression model, and the explanatory power of the independent variables on the dependent variable is $17.4 \%$. The logistic regression model is used to examine whether employment-preparation activities affect the size of the companies that employ new graduates.

Among the three sub-items of preparatory activities, the odds ratio of taking standardized English exams is 1.369, which means that taking a standardized English exam increases the odds of working at a major company by 1.369 times. However, the odds ratio of obtaining certificates is less than one. The $p$-value is 0.000 , which is less than 0.05 . Thus, having certificates does not necessarily help college graduates get jobs with large companies. More precisely, we find that students with a certificate have lower odds of working for a big company. When comparing the variables' degrees of influence on company size, taking standardized English exams has the greatest influence.

Next, we conduct a multiple regression of wage level on employment-preparation activities to test Hypothesis 2-3. The results of the analysis are summarized in Table 9.

Table 9. Results of regressing wage level on preparatory activities.

\begin{tabular}{cccc}
\hline & $\boldsymbol{\beta}$ & S.E. & $\mathbf{t}$ \\
\hline Internship experience & $0.051^{* *}$ & 0.013 & 5.722 \\
Obtaining certificates & $0.053^{* *}$ & 0.009 & 6.019 \\
Taking standardized English exams & $0.043^{* *}$ & 0.009 & 4.862 \\
Constant & & 0.007 & 773.273
\end{tabular}

R-Squared $=0.043$, Adjusted R-Squared $=0.042, \mathrm{df1}=3, \mathrm{~F}=29.356$, $\mathrm{p}=0.000$, Durbin-Watson $=1.937$

Dependent variable: wage levels. ${ }^{* * *}, * *$, and ${ }^{*}$ denote statistical significance at the $1 \%, 5 \%$, and $10 \%$ levels, respectively.

According to Table 9, the overall explanatory power (i.e., the adjusted R-squared) of employment-preparation activities over wage levels is $4.2 \%$. The F-statistic is 29.356 , the corresponding $p$-value is 0.000 , the Durbin-Watson statistic is 1.937, and the VIF is 1.002 1.011(<10.0). Thus, this multiple regression equation is statistically significant, and the independence of the residuals is secured without a multicollinearity problem. As a result, we find that internship experience, obtaining certificates, and taking standardized English exams, the three preparatory activity sub-factors, have statistically significant positive effects on wage levels. Specifically, the standardized coefficient $\beta$ of internship experience is 0.051 , that of obtaining certificates is 0.053 , and that of taking standardized English exams is 0.043 , indicating that these factors have statistically significant positive effects on wage levels. Comparing the degree of influence on wage levels, the most influential factor is obtaining certificates, followed by internship experience and taking standardized English exams. However, the differences among the three factors are insignificant.

Next, we conduct a multiple regression of job satisfaction on employment-preparation activities to test Hypothesis 2-4. The results of the analysis are summarized in Table 10. 
Table 10. Results of regressing job satisfaction on preparatory activities.

\begin{tabular}{cccc}
\hline & $\boldsymbol{\beta}$ & S.E. & $\mathbf{t}$ \\
\hline Internship experience & $0.056^{* *}$ & 0.026 & 6.355 \\
Obtaining certificates & $0.041^{* *}$ & 0.019 & 4.605 \\
Taking standardized English exams & -0.002 & 0.019 & -0.228 \\
Constant & & 0.013 & 278.514 \\
\hline
\end{tabular}

R-Squared $=0.072$, Adjusted R-Squared $=0.071, \mathrm{df1}=3, \mathrm{~F}=20.120$, $\mathrm{p}=0.000$, Durbin-Watson $=1.970$

Dependent variable: Job satisfaction. ***, **, and * denote statistical significance at the $1 \%, 5 \%$, and $10 \%$ levels, respectively.

According to Table 10, the overall explanatory power (the adjusted R-squared value) of employment-preparation activities on job satisfaction is $7.1 \%$. The F-statistic is 20.120 , and the corresponding $p$-value is 0.000 . The Durbin-Watson statistic is 1.970, and the VIF is 1.002 1.011(<10.0). Thus, this multiple regression equation is statistically significant, and the independence of the residuals is secured without multicollinearity. As a result, we find that, among the three sub-factors, internship experience and certificate acquisition have statistically significant positive effects on job satisfaction, whereas taking standardized English exams has no significant effect. The standardized coefficient $\beta$ of internship experience is 0.056 , and that $\beta$ of obtaining certificates is 0.041 .

In summary, employment-preparation activities by Korean college graduates are found to have a significant positive effect on initial labor-market performance.

\section{Conclusions}

\subsection{Summary of the Study and Discussion}

First, we found a meaningful positive correlation between college education quality (both experienced and perceived by graduates) and the four sub-factors of initial labor-market performance-namely, job quality (regular/non-regular), company size (major company/SME), wage level, and job satisfaction. Specifically, vocational education and training experience, one of the three sub-factors of education quality, positively influences job quality, wage levels, and job satisfaction but has no influence on company size. However, studying language abroad positively influences all the factors-job quality, company size, wage level, and job satisfaction.

These results support previous studies such as Joo [18], who demonstrated the significant influence of vocational training experience in college on higher wage employment opportunities. Hwang and Baek [11], who showed that vocational training experience has a significant effect on finding a job with a major company or a regular job. That study showed that satisfaction with such training has a significant effect on labor-market performance; and Park and Cheon [52] found that studying language abroad positively affects employment at a major company or in a regular job. Nevertheless, this study is more meaningful than previous studies for two reasons. First, it used the most recent social data available by expanding the range of research subjects to graduates of twoand three-year vocational colleges, as well as those of four-year universities. Second, it broke down labor-market performance - the single dependent variable typically used in other studies-into four sub-factors. Thus, this further clarifies the effects of college education on the dependent variable.

Overall, the findings of the detailed analysis showed that, among the sub-factors of college education quality, vocational training experience has the greatest influence on three dependent variable sub-factors, excluding job satisfaction (logistic coefficient B for job quality: 0.160; B for size of the company: $0.222 ; \beta$ from multiple regression analysis for the wage level: 0.137$)$. Studying language abroad has the second-greatest influence on job quality and company size. Thus, based on these results, vocational education and training should be more systematically provided for college students across 
different majors, regions, and job prospects. Simultaneously, policies should be considered for colleges or other institutions to fund more opportunities for graduates to study language abroad.

Although the results clearly demonstrate that vocational training and studying a language abroad affect labor-market performance and job quality positively, reality reflects otherwise. Among the 12,799 subjects surveyed in 2016, only 32.96\% (4212 subjects) had experience in vocational education and training and 13.26\% (1694 subjects) had studied language abroad. Owing to the lack of these opportunities, many young Koreans spend large sums of money on additional extracurricular education in their attempts to enter the labor market [58]. This, in turn, aggravates inequality in education, a problem that spans from secondary school students applying to colleges to older students, who are currently enrolled and attempting to enter the labor market. In some cases, this problem persists even after graduation. To solve this problem gradually and to improve labor-market performance more comprehensively, more institutional devices and policies should focus on the opportunities, such as vocational training and studying language abroad, that have been proven to increase the quality of employment.

Second, graduates' employment-preparation activities were shown to have significantly positive or negative influences on the four initial labor-market performance sub-factors (job quality, company size, wage level, and job satisfaction). Specifically, internship experience, a sub-factor of employment-preparation activities, has a significant influence on all four. Obtaining certificates, however, has a significantly positive influence on job quality, wage level, and job satisfaction but a negative influence on company size. Finally, taking standardized English exams influences job quality, company size, and wage level significantly positively but influences job satisfaction negatively.

These results generally support those of Jung and Cho [25], who concluded that internship experience has a positive influence on labor-market performance. Park and Ban [17] concluded that obtaining certificates does not really help in obtaining a good position, such as at a major company; and Choi [32] concluded that standardized English exam scores positively influence graduates' wage levels, job satisfaction, and so on. In particular, many prior studies reach contradictory conclusions regarding certificates' influence on finding a job. In this study, certificates are shown to have a negative influence on employment quality, and, thus, it is vital to choose certificates that have domestic public confidence and are recognized professionally. However, we should also mention Lee et al.'s [30] result, who concluded that the effects vary depending on the certificate's characteristics. The internship experience effect is also reported to vary depending on its type, quality, and details. We also refer to Jung and Cho [25], who concluded that internship experiences that correspond or are connected to one's major positively influence job-seeking activity results.

\subsection{Contributions and Limitations}

Based on its findings and discussions, this study suggested more effective methods for advancing graduates' initial labor-market performances, improving college education, and supporting preparatory activities, among others. Previous studies have mostly focused on personal characteristics (gender, age, level of education, major, etc.) in analyzing the variables that cause graduates' employment outcomes. Furthermore, in considering employment outcomes, they have mostly focused on quantitative outcomes (employment success rate, time to secure employment, duration of employment, etc.). However, few demonstrate the influence of variables related to characteristic-based factors, namely, the degree of readiness for employment and job-seeking efforts. These may include vocational training, studying language abroad, internship experience, certificate acquisition, taking an officially recognized English examination, and so on.

Moreover, comparatively few studies have demonstrated qualitative employment outcomes, such as quality of employment, wage levels, workplace, and job satisfaction.

This study confirms and supports the few existing studies, supplementing and deepening the discussion, while expanding the surveyed subjects to include all types of college graduates in Korea. Using a large quantity of recently collected data, this study found relationships among many qualitative 
and technical variables. Thus, the significance of these findings can be verified in this regard. It would be an honor if these findings were used as reference data or as a valid theoretical and operational guideline for establishing more rational, future-oriented policies. Findings could spark detailed strategies to solve unemployment issues by improving Korean college graduates' initial labor-market performance, strengthening job security, and offering sustainable jobs [59].

Additionally, this study suggests that broad transformative change and leadership in college education has large implications for college and university administrators. Trading theoretical for practical experience will have an impact on how academies interact with external communities. This shift will certainly generate leaders who are interdisciplinary and long-range thinkers, as well as connected to the higher education decision-making structure. College and university planners are uniquely positioned and hold unprecedented responsibility to ensure that higher-education institutions fulfill their social responsibility to create a healthy, just, and sustainable world. Furthermore, policymakers must be able to understand and articulate the advantages of higher-education institutions leading the creation of a sustainable society for all stakeholders. These include internal decision-makers and other stakeholders (e.g., faculty, operational personnel, students) and external stakeholders (e.g., parents, alumni, local and regional communities, future employers, funders, and accreditation organizations).

However, this study has a few limitations. First, it analyzed a social survey carried out on 12,799 college graduates as part of the 2016 GOMS. The sample is large, but it is still only 3.5\% of all Korean graduates. Thus, these findings do not reflect all graduates' employment situations, and discretion is needed when generalizing these conclusions [60].

Second, the 2016 GOMS includes 1297 survey items. An enormous amount of data on Korean college graduates' employment has been collected and organized. This data contains very specific, diverse, and detailed information. Given the size of the sample, and because of time and other constraints faced by this study, it is impossible to read or analyze all of it. The variables used in this study are just some of the phenomena or factors that may affect issues regarding the employment of Korean graduates. In reality, there are many other influential factors that relate to graduates' training and education, job-seeking activities, short- and long-term labor-market performance, etc. More in-depth measuring methods must be developed to demonstrate such various and detailed factors [59].

Third, because our survey began in 2016, we utilized variables constructed after 2016. However, the data period could be extended. In interpreting our statistical findings, some variables with low statistical significance and results with low R-squared values should be treated with caution. Furthermore, our regression analysis could be enhanced with more control variables, such as gender, age, and field of study. Such extensions are left for future work.

Finally, because of the individual characteristic attributes and other variables omitted from our empirical model, our analysis is limited to the interpretation of the causal relationship. However, because of the data accessibility limitations with regard to these characteristics, we leave this work to future extended study.

Consequently, future studies should use multifaceted approaches to survey a wider range of subjects and to develop specific, advanced, and qualitative categories that demonstrate labor-market performance in the short, medium, and long term from many different perspectives [60-68]. Doing so will hopefully lead to additional meaningful research results and conclusions.

Author Contributions: C.Y.C. designed the research. M.Y. performed the research and analyzed the data. M.Y. wrote the paper. D.C. and J.Y. revised the paper. All authors read and approved the final manuscript.

Funding: This work was supported by the research program of Kookmin University in Korea.

Conflicts of Interest: The authors declare no conflicts of interest. 


\section{References}

1. Becker, G.S. Investment in human capital: A theoretical analysis. J. Polit. Econ. 1962, 70, 9-45. [CrossRef]

2. Card, D. The causal effect of education on earnings. Handb. Labor Econ. 1999, 3, 1801-1863.

3. Psacharopoulos, G. Returns to education a further international update and implications. J. Hum. Resour. 1985, 20, 583-604. [CrossRef]

4. Psacharopoulos, G. Returns to investment in education: A global update. World Dev. 1994, 22, $1325-1343$. [CrossRef]

5. Psacharopoulos, G.; Patrinos, H.A. Returns to Investment in Education: A Further Update (English). Policy, Research Working Paper Series No. WPS 2881. Washington, DC, World Bank. Available online: http://documents.worldbank.org/curated/en/512891468739485757/Returns-to-investmentin-education-a-further-update (accessed on 21 March 2018).

6. Montenegro, C.E.; Patrinos, H.A. Comparable Estimates of Returns to Schooling around the World (English). Policy Research Working Paper No. WPS 7020. Washington, DC: World Bank Group. Available online: http://documents.worldbank.org/curated/en/830831468147839247/Comparable-estimatesof-returns-to-schooling-around-the-world (accessed on 14 April 2019).

7. Peet, E.D.; Fink, G.; Fawzi, W. Returns to education in developing countries: Evidence from the living standards and measurement study surveys. Econ. Educ. Rev. 2015, 22, 69-90. [CrossRef]

8. Patrinos, H.A. Estimating the return to schooling using the Mincer equation. Iza World Labor Inst. Study Labor (Iza) 2016, 17, 278. [CrossRef]

9. Jeon, J.Y. Education-job mismatch raise social costs: Youths' downgrade employment trend. Employ. Issue 2012, 7, 37-49.

10. Chae, C.K.; Kim, T.G. Determinants of employment status of university (college) graduates youth. J. Labor Educ. 2009, 28, 89-107.

11. Hwang, Y.J.; Baek, B.B. Determinants of employment status of university graduates youth. J. Vocat. Educ. Train. 2008, 11, 1-23.

12. Altonji, J.; Dunn, T.A. Using siblings to estimate the effect of school quality on wages. Rev. Econ. Stat. 1996, 78, 665-671. [CrossRef]

13. Belzil, C.; Hansen, J. Unobserved ability and the return to schooling. Econometrica 2002, 70, $2075-2091$. [CrossRef]

14. Gensowski, M. Personality, IQ, and lifetime earnings. Labour Econ. 2018, 51, 170-183. [CrossRef]

15. Anderson, A.H. Successful training practice: A manager's guide to personnel development. Asia Pac. J. Hum. Resour. 1993, 33, 1-23.

16. Kluve, J. The effectiveness of European active labor market programs. Labour Econ. 2010, 17, 904-918. [CrossRef]

17. Park, J.K.; Ban, G.B. Empirical age-earnings profiles. J. Labor Econ. 1990, 8, 202-229.

18. Joo, H.J. Individual and College Effects on Earnings of New Graduates. Ph.D. Thesis, Korea University, Seoul, Korea, 2010.

19. Jang, K.Y. Determinants of the First Job Attainment for College Graduates in Korea: Effect of Socio-economic Status, Educational Characteristics and Individual Preparedness. Ph.D. Thesis, Hanyang University, Seoul, Korea, 2008.

20. Astin, A.W. What Matters in College? Four Critical Years Revisited; Jossey-Bass Publishers: San Francisco, CA, USA, 1993.

21. Jo, Y.S. Study on the effects of university student's work value on learner centered career preparation behavior, school wide career preparation behavior and employment outcomes. J. Learn. Cent. Curric. Educ. 2018, 18, 53-78.

22. Ashenfelter, O.; Zimmerman, D. Estimates of the return to schooling from sibling data: Fathers, sons and brothers. Rev. Econ. Stat. 1997, 79, 1-9. [CrossRef]

23. Ashenfelter, O; Rouse, C.E. Income, schooling and ability: Evidence from a new sample of identical twins. Q. J. Econ. 1998, 113, 253-284. [CrossRef]

24. Bronars, S.; Oettinger, G. Estimates of the return to schooling and ability: Evidence from sibling data. Labour Econ. 2006, 13, 19-34. [CrossRef] 
25. Jung, K.D.; Cho, M.H. A study on the effect of working experience while in college on the labor market outcomes: Focused on the wage and job mismatch. Korean Soc. Public Adm. 2016, 27, 237-259.

26. Roh, J.T.; Hur, M.S. A qualitative study on the license acquisition of university graduates and employment: Focus on the perception of enterprise personnels. J. Competency Dev. Learn. 2013, 8, 54-73.

27. Jang, W.S. An exploration on the changes of college students' labor market preparation behavior. J. Labor Educ. 2004, 23, 103-118.

28. Ihm, C.S.; Yoo, J.B. Determinants of college graduate employment selection in service industry. J. Educ. Adm. 2004, 22, 311-332.

29. Lee, Y.B. unemployment and monetary policy. J. Econ. Persp. 1997, 11, 33-49.

30. Lee, S.T.; Kim, J.Y. Estimating the returns to schooling: Some econometric problems. Econometrica 1977, 45, $1-22$.

31. Chatelain, J.; Ralf, K. Inference on Time-invariant Variables Using Panel Data: A Pre-test Estimator with an Application to the Returns to Schooling; PSE Working Papers hal-00492039; HAL: London, UK, 2010.

32. Choi, I.S. A Empirical study on the Determinants of College Graduates Employment Outcomes. Ph.D. Thesis, Dankook University, Seoul, Korea, 2012.

33. Kang, S.H. The effects of job search methods of youth on employment outcomes. J. Career Educ. 2010, 23, 77-99.

34. Card, D. Using Geographic Variation in College Proximity to Estimate the Return to Schooling; Working Paper No. 4483; NBER: Cambridge, MA, USA, 1993.

35. Conneely, K.; Uusitalo, R. Estimating Heterogeneous Treatment Effects in the Becker Schooling Model. Unpublished Discussion Paper; Princeton University Industrial Relations Section: Princeton, NJ, USA, 1997.

36. Kim, D.S. The path of entry and early labor market performance of college graduates. In 2011 Employment Trend Survey Symposium of Korea Employment Information Service; Columbia University: New York, NY, USA, 2011.

37. Dickson, M.; Smith, S. What Determines the Return to Education: An Extra Year or Hurdle Cleared? Working Paper No. 11/256; University of Bristol: Bristol, UK, 2011.

38. Brooke, J.; Paul, P.; Russell, D.W.; Price, J.L. Discriminant validation of measures of job satisfaction, job involvement and organizational commitment. J. Appl. Psychol. 1988, 73, 139-145. [CrossRef]

39. Kim, J.S. The difference of pre-employment activities and its effect on transition of four-year college graduates. J. Educ. Stud. 2009, 40, 141-165.

40. Kil, H.J.; Choi, Y.M. The effects of individual and college characteristics on graduates employment status. J. Labor Educ. 2014, 33.

41. Choi, B.Y.; Kim, S.H. An individual's work values in career development. J. Employ. Couns. 2013, 50, $154-165$.

42. Cha, S.H.; Chu, H.J. The effect of education and skill mismatch on wage, job satisfaction, and intention to leave. J. Econ. Financ. Educ. 2010, 19, 177-215.

43. Park, J.H. Are temporary jobs a port of entry into permanent employment? Evidence from matched employer-employee. Int. J. Manpow. 2011, 32, 879-899.

44. Ichino, A.; Winter-Ebmer, R. Lower and Upper Bounds of Returns to Schooling: An Exercise in IV Estimation with Different Instruments. 1998. Available online: https://papers.ssrn.com/sol3/papers.cfm?abstract_id= 141407 (accessed on 15 May 2019).

45. Meghir, C.; Palme, M. Educational reform, ability, and family background. Am. Econ. Rev. 2005, 95, 414-424. [CrossRef]

46. Spence, M. Job market signaling. Q. J. Econ. 1973, 87, 355-374. [CrossRef]

47. Becker, G.S. Human Capital: A Theoretical and Empirical Analysis, With Special Reference to Education; Columbia University Press: New York, NY, USA, 1964.

48. Becker, G.S.; Tomes, N. Human capital and the rise and fall of families. J. Labor Econ. 1986, 4, S1-S39. [CrossRef] [PubMed]

49. Chae, G.M. Statistical Analysis of Social Science; The Academy: Paju, Korea, 2014.

50. Choi, H.N. Analysis of Factors Influencing the First Labor Market Performance of University Graduates by Location. Master's Thesis, Dong-A University, Busan, Korea, 2019.

51. Kim, D.H. The Study on the Effectiveness of Active Labor Market Policy Programs for Youth in Korea. Ph.D. Thesis, Sungkyunkwan University, Seoul, Korea, 2019. 
52. Park, M.S.; Cheon, D.H. Analyzing the effectiveness of the youth employment policy-Focusing on the youth internship program for small and medium-sized enterprises and public institutions. Korean Soc. Public Adm. 2018, 29, 57-81.

53. Gilson, L.; Durick, T.K. Earnings differentials between public, private and joint sector in Punjab (India). J. Dev. Stud. 1988, 25, 97-111.

54. Choi, Y.J.; Choi, S.B.; Lee, M.J. The social psychological meaning of occupation-related identities among generations. Korea J. Popul. Stud. 2011, 34, 55-84.

55. Curry, J.P.; Wakefield, D.S.; Price, J.L.; Mueller, C.W. On the causal ordering of job satisfaction and organizational commitment. Acad. Manag. J. 1986, 29, 847-858.

56. Ellingson, J.E.; Gruys, M.L.; Sackett, P.R. Factors related to the satisfaction and performance of temporary employees. J. Appl. Psychol. 1998, 83, 913-921. [CrossRef]

57. Fulford, M.D.; Enz, C.A. Human resources as a strategic partner in multiunit-restaurants. Cornell HotelRestaur. Adm. Q. 1995, 36, 24-29. [CrossRef]

58. Hong, J.M. Analyzing the Effect of Internship Experience during College on Post-graduate First Job Quality. Master's Thesis, Sookmyung Women's University, Seoul, Korea, 2018.

59. Koo, J.H.; Khan, F.; Jang, D.D.; Jung, H.J. Dynamic characterization and modeling of magneto-rheological elastomers under compressive loadings. Smart Mater. Struct. 2010, 19, 11-29. [CrossRef]

60. Kang, S.H.; Park, S.J. Coordination of school education and duties of young people. In Occupational Employment Survey and Youth Panel Symposium. Korea Employment Information Service; Donga: Seoul, Korea, 2002.

61. Kim, H.W.; Lee, J.G. Study of influence by participating overseas employment program on job quality. J. Employ. Career 2017, 7, 1-20. [CrossRef]

62. Chung, C.Y.; Liu, C.; Wang, K.; Zykaj, B.B. Institutional monitoring: Evidence from the F-score. J. Bus. Financ. Acc. 2015, 42, 885-914. [CrossRef]

63. Liu, C.; Chung, C.Y.; Sul, H.K.; Wang, K. Does hometown advantage matter? The case of institutional blockholder monitoring on earnings management in Korea. J. Int. Bus. Stud. 2018, 49, 196-221. [CrossRef]

64. Choi, P.M.S.; Chung, C.Y.; Hwang, J.H.; Liu, C. Heads I Win, Tails You Lose: Institutional Monitoring of Executive Pay Rigidity. J. Financ. Res. 2019, 42, 789-816. [CrossRef]

65. Choi, P.M.S.; Chung, C.Y.; Liu, C. Self-attribution of overconfident CEOs and asymmetric investment-cash flow sensitivity. N. Am. J. Econ. Financ. 2018, 46, 1-14. [CrossRef]

66. Chung, C.Y.; Hur, S.K.; Liu, C. Institutional investors and cost stickiness: Theory and evidence. N. Am. J. Econ. Financ. 2019, 47, 336-350. [CrossRef]

67. Chung, C.Y.; Jung, S.; Young, J. Do CSR activities increase firm value? Evidence from the Korean market. Sustainability 2018, 10, 3164. [CrossRef]

68. Cho, S.J.; Chung, C.Y.; Young, J. Study on the Relationship between CSR and Financial Performance. Sustainability 2019, 11, 343. [CrossRef]

(C) 2020 by the authors. Licensee MDPI, Basel, Switzerland. This article is an open access article distributed under the terms and conditions of the Creative Commons Attribution (CC BY) license (http://creativecommons.org/licenses/by/4.0/). 